Brit. J. industr. Med., 1954, 11, 105.

\title{
TUMOURS OF THE URINARY BLADDER IN DOGS AFTER INGESTION OF 4-AMINODIPHENYL
}

\author{
BY \\ A. L. WALPOLE, M. H. C. WILLIAMS, and D. C. ROBERTS \\ From Imperial Chemical Industries Ltd., Medical Department and Biological Laboratories, \\ Hexagon House, Manchester
}

(RECEIVED FOR PUBLICATION FEBRUARY 3, 1954)

\begin{abstract}
4-Aminodiphenyl was discovered by Hofman in the residues of aniline manufacture in 1862, and yet it is only in recent years that it has come to be considered for use in the organic chemical industry in England. In 1950 it seemed to us that this amine might have been partly responsible for " aniline cancers" of the bladder amongst dyestuff workers in Germany before 1920 and that its manufacture and use at the present day, if undertaken without adequate precautions, would involve a hazard to those concerned. We therefore started an investigation into its carcinogenic potentialities in rats and dogs.

The results of our experiments with rats have already been published in this journal (1952). Tumours of the liver, intestine, and mammary gland were found following the repeated subcutaneous injection of 4-aminodiphenyl in arachis oil. The present paper describes the effects of feeding the amine to dogs.
\end{abstract}

\section{Experimental Details}

Two male Beagle litter-mates aged 7 months were used in the experiment. They were fed on minced raw meat and houndmeal, supplemented with vegetables, bone meal, salt and cod-liver oil, as were the rest of the pack. 4-Aminodiphenyl, (b.p. $302^{\circ} \mathrm{C}$. at atmospheric pressure) was administered on a weight basis in capsules by mouth. The animals were dosed once daily, six days a week, and details were as follows :

Both animals gained weight during the experiment; dog 457 weighed $8.4 \mathrm{~kg}$. at the start and rose to $13.2 \mathrm{~kg}$. at death, whereas dog 458 gained $3 \cdot 2 \mathrm{~kg}$. from $10 \mathrm{~kg}$. Poor appetite or loss of weight were used as indications either for the lowering of the dose level or for temporary cessation of dosing. On January 1, 1952, we considered that the results
DOSES OF 4-AMINODIPHENYL

\begin{tabular}{|c|c|c|c|c|c|}
\hline \multirow[b]{2}{*}{$\begin{array}{c}\text { Dose } \\
\text { Level } \\
\text { (mg./kg.) }\end{array}$} & \multirow[b]{2}{*}{$\begin{array}{c}\text { Time of } \\
\text { Administration }\end{array}$} & \multicolumn{2}{|c|}{ Dog 457} & \multicolumn{2}{|c|}{ Dog 458} \\
\hline & & \begin{tabular}{|l} 
Dose \\
(g.)
\end{tabular} & $\begin{array}{l}\text { Cumulative } \\
\text { Total Dose } \\
\text { (g.) }\end{array}$ & \begin{tabular}{|c} 
Dose \\
(g.)
\end{tabular} & \begin{tabular}{|c|} 
Cumulative \\
Total Dose \\
(g.)
\end{tabular} \\
\hline $\begin{aligned} 20.0 \\
10.0 \\
7.5 \\
5.0 \\
\text { Nil } \\
5.0\end{aligned}$ & $\begin{array}{c}27.11 .50-7.1 .51 \\
8.1 .51-27.251 \\
28.2 .51-28.3151 \\
29.3 .51-31.12 .51 \\
1.1 .52-29.6 .52 \\
30.6 .52-10.2 .53\end{array}$ & \begin{tabular}{|c|}
4.80 \\
3.42 \\
1.57 \\
10.43 \\
Nil \\
10.04
\end{tabular} & $\begin{array}{r}4 \cdot 80 \\
89.22 \\
9 \cdot 79 \\
20 \cdot 22 \\
20 \cdot 22 \\
30 \cdot 26\end{array}$ & \begin{tabular}{|c|}
6.00 \\
4.46 \\
1.44 \\
10.95 \\
Nil \\
10.71
\end{tabular} & $\begin{array}{r}6.00 \\
10.46 \\
11.90 \\
22.85 \\
22.85 \\
33.56\end{array}$ \\
\hline
\end{tabular}

obtained in rats up to that time did not warrant the continuance of the experiment with dogs, and dosing was stopped. Then, on June 1, 1952, 18 months after the beginning of the experiment, dog 457 was noticed to have haematuria, which persisted for a month. Since dogs fed with benzidine in many laboratories have failed to develop tumours when observed over five years, we found it hard to believe that haematuria so early in our experiment was due to the presence of a tumour. However, dosing at $5 \mathrm{mg}$. $/ \mathrm{kg}$. was begun again on June 30 , 1952, and continued until February 10, 1953.

Dog 457 had haematuria at intervals after November 5, 1952, but both dogs remained quite healthy, ate well, and maintained their weight until September, 1953, when dog 457 lost its appetite, had a series of fits and, after a few days, became unconscious. On the same day, dog 458 also became unconscious. A clinical diagnosis of terminal uraemia was made in each case and both dogs were killed on September 2, 1953, two years nine months after the start of oral dosing with 4-aminodiphenyl.

\section{Post-mortem Examination}

Dog 457 was well nourished, and there were no abnormal external appearances, except for much frothy saliva in the mouth. (There had been a generalized convulsion within a few minutes of death.) 
The thoracic contents appeared normal, except for congestion of both lungs. There was no pericarditis and no serous effusions.

The stomach appeared normal as did the rest of the intestinal tract, except for a small quantity of blood in the lumen of the small gut.

The liver, spleen, pancreas, adrenals, kidneys, ureters, and prostate appeared normal. The brain was not examined.

The bladder was contracted and, on palpation, felt as if it were a solid organ. The surface appeared normal and no pelvic adhesions were present. . On opening the organ a very small quantity of urine was released which was not bloodstained. The bladder lumen was nearly occluded by multiple epithelial tumours growing from the bladder wall. These tumours showed their greatest development in the dome of the bladder, and were relatively sparse at the base, where apparently normal mucosa could be seen between them. The tumours were grey ; some were pedunculated, but the majority were sessile.

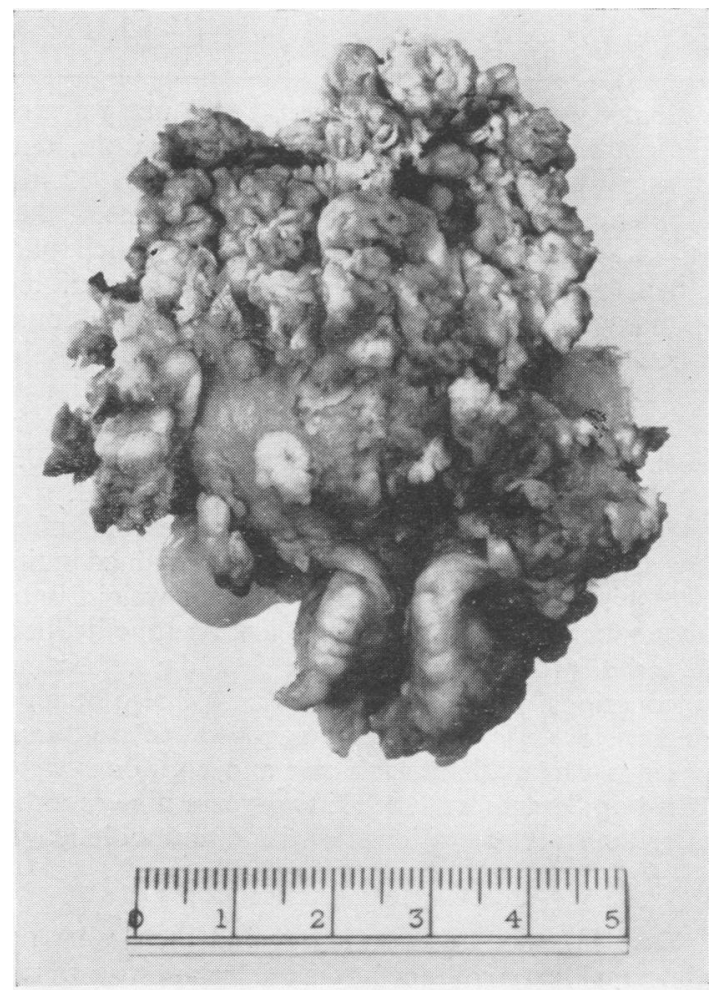

Fig. 1.-Mucosal surface of the bladder of $\operatorname{dog} 458$, showing papillomatosis. The tumours are large and closely packed in the upper two-thirds of the organ, and relatively sparse in the lowest third. Natural size.
Dog 458 was well nourished and there were no abnormal external appearances.

The thoracic contents appeared normal; there was no pericarditis and no serous effusions were present.

Submucous haemorrhages were present in the stomach and in the intestines, while the spleen and pancreas appeared normal. The liver was congested and fatty. The adrenals, ureters, and prostate appeared normal, while the kidneys were congested. The brain was not examined. The abnormal findings in the liver were confirmed by microscopy.

The bladder was globular in shape, contracted, and the wall thickened. The surface appeared normal and there were no pelvic adhesions. On opening the organ, approximately $10 \mathrm{ml}$. of urine were released, This was not bloodstained.

Multiple, closely packed tumours were present over the whole internal surface of the upper twothirds of the organ, while in the lowest third the tumours were fewer, relatively large areas of apparently normal mucosa appearing between them The tumours were grey, most were pedunculated, but some were sessile.

The gross appearance of the organ is seen in Fig. 1 .

Microscopic Examination of the Bladders.-The tumours were similar to those previously described by Bonser (1943), the bladder epithelium showing a graded series of changes from simple hyperplasia to infiltrating carcinoma.

The simplest change was a thickening of the epithelium together with some swelling of the cells. Microcysts caused, presumably, by degeneration of cells were frequent.

With increased thickening of the epithelium, a mass of cells either acquired a connective tissue core, becoming a pedunculated papilloma (Fig. 3), or formed an irregular sessile mass projecting into the lumen of the bladder. In some cases projections of epithelial cells passed down into the subjacent connective tissue (Fig. 4).

Larger growths, both simple and malignant, were also found. These were either transitional-cell tumours, anaplastic tumours showing much cellular pleomorphism (Fig. 5), or tumours composed of small cells with small, round, closely packed, deeply staining nuclei, a small amount of basophilic cytoplasm and indefinite cell boundaries. Mixed structure was common and tubule formation frequently seen (Fig. 6).

In dog 457 infiltration of the wall of the bladder by tumour cells was limited to the sub-epithelial connective tissue, stopping just short of the muscle 


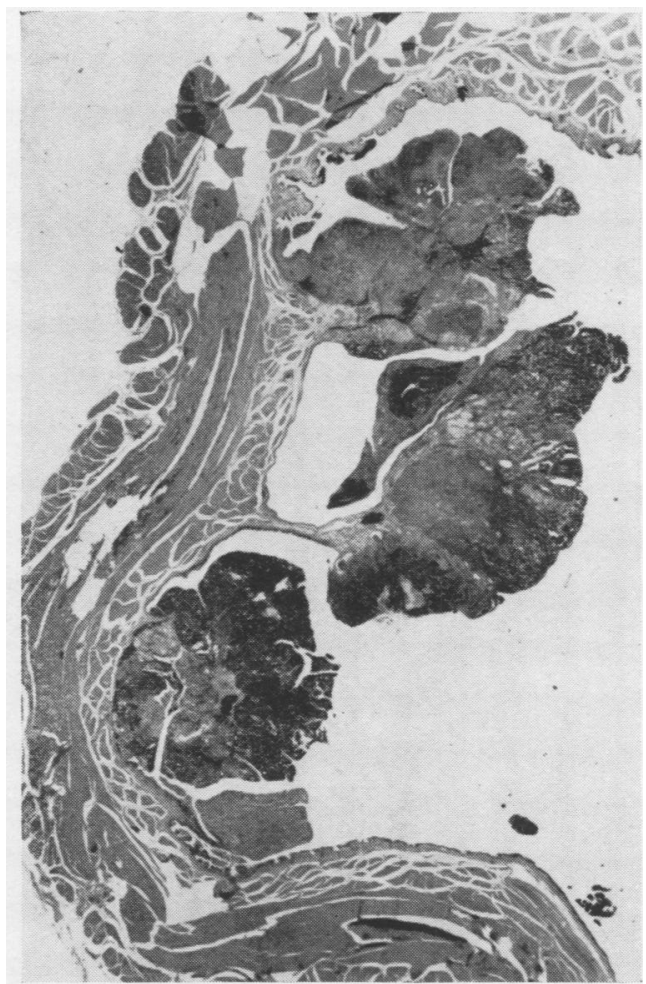

Fig. 2

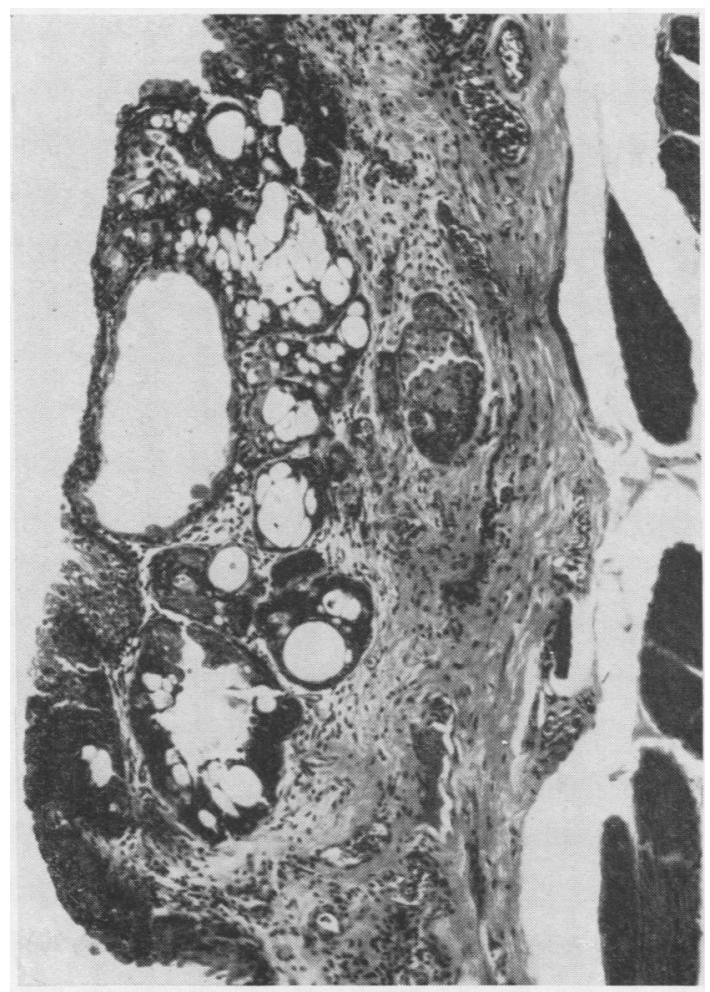

FIG. 4

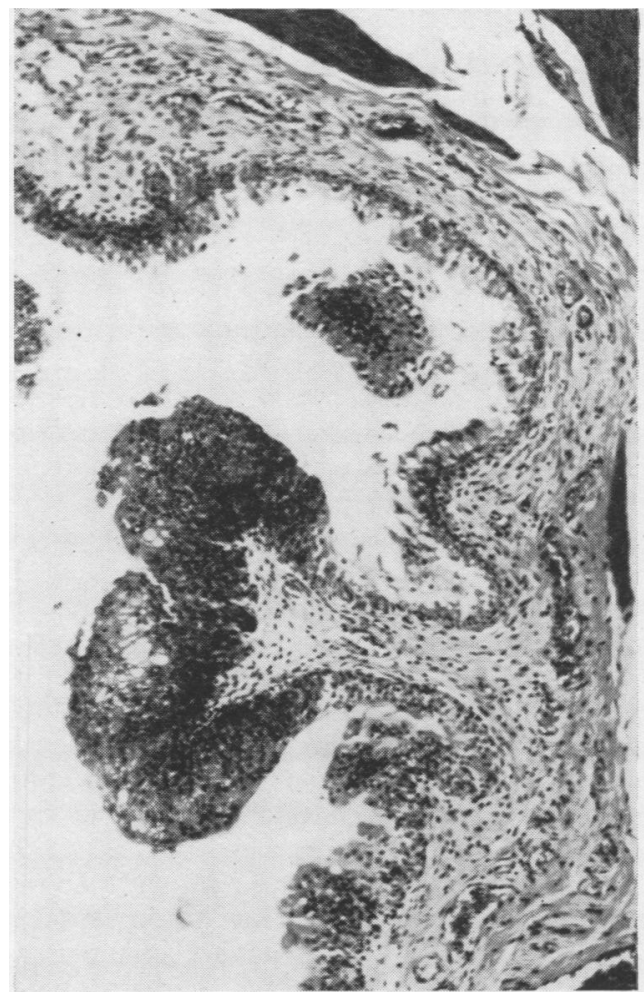

FIG. 3

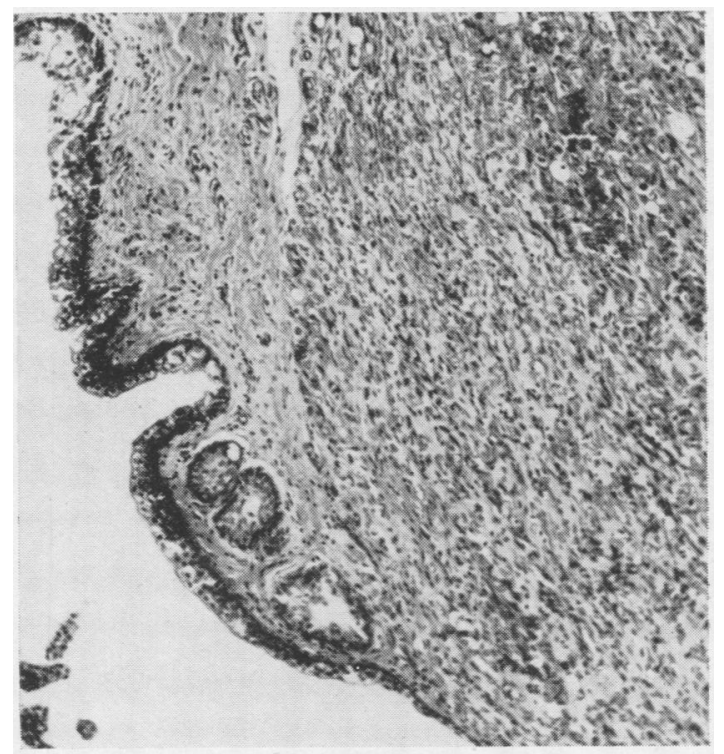

FIG. 5

Fig. 2.-Section of bladder of dog 457 with pedunculated papilloma in centre and more sessile growths on either side. $\times 4$

Fig. 3.-A very early papilloma in the bladder of dog $457 . \times 90$.

FIG 4-Gross thickening of the epithelium of the bladder of dog 457 with microcyst formation. Groups of epithelial cells pass down into the subepithelial connective tissue. $\times 90$.

Fig. 5.-Edge of an area of anaplastic carcinoma in the bladder of $\operatorname{dog} 457 \times 90$. 
bundles, but in dog 458 there was deep infiltration, carcinoma cells being found deep in the musculature of the bladder wall but not reaching to the surface of the organ (Fig. 7).

\section{Conclusions}

The occurrence of bladder tumours in these two dogs, two years nine months after the start of dosing with 4-aminodiphenyl, is more significant if the records of the remainder of our Beagle pack are considered. Haematuria has never been observed. Thirty animals of the pack are now 3 to 9 years old and in six others over 3 years of age which have died from various causes and have been examined post mortem, no bladder tumours have been found.

Bladder tumours have been produced in dogs by feeding with $\beta$-naphthylamine, benzidine, 2-acetylaminofluorene, $\mathrm{N}: \mathrm{N}$-dimethyl-4-aminoazobenzene and 4-amino-3:2'-azotoluene. It is interesting to compare the appearance of such tumours in our two dogs after 33 months, when only 30 to $34 \mathrm{~g}$. of 4-aminodiphenyl had been given, with the results obtained with these other amines. Spitz, Maguigan, and Dobriner (1950) and Spitz (personal communication) found that the three longest survivors of seven dogs given approximately $325 \mathrm{~g}$. of benzidine by mouth developed papillomas and carcinomas of the bladder after 84, 96, and 120 months respectively. Morris and Eyestone (1953) obtained bladder tumours in four Beagles at $68-91$ months with total doses of 90-198 g. of 2-acetylaminofluorene, but no tumour in another which was given only $45 \mathrm{~g}$. of the amine and observed for 87 months. From Nelson and Woodard's paper (1953) it is not clear what total dose of $\mathrm{N}: \mathrm{N}$-dimethyl-4-aminoazobenzene and 4-amino-3:2-azotoluene these authors gave, but their four dogs with bladder tumours died after $30,38,43$, and 48 months respectively. Hueper and Wolfe (1937), and Hueper, Wiley, and Wolfe (1938), with total doses of $\beta$-naphthylamine ranging from 58 to $130 \mathrm{~g}$. obtained bladder tumours in a minimum time of 18 months. These lesions, however, were first detected by cystoscopy, and not until later was haematuria observed. It seems likely that tumours were already forming in the bladders of our dogs when haematuria was seen at $\mathbf{1 8}$ months. Bonser (1943), who obtained similar tumours in 44,50 , and 60 months in dogs given massive doses of $\beta$-naphthylamine, also observed haematuria some time before death. Gehrmann, Foulger, and Fleming (1949) have reported the production of a bladder tumour with $15 \mathrm{~g}$. of $\beta$-naphthylamine, but this did not appear until some six and a half years after the start of dosing.

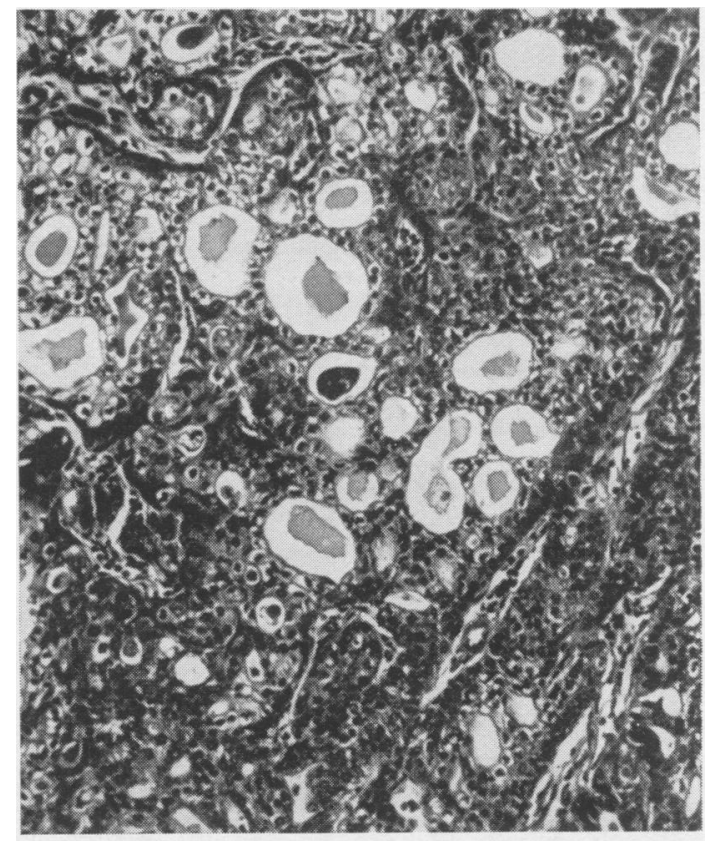

FIG. 6.-Tubule formation in a malignant papilloma of mixed structure in the bladder of dog $458 . \times 150$.

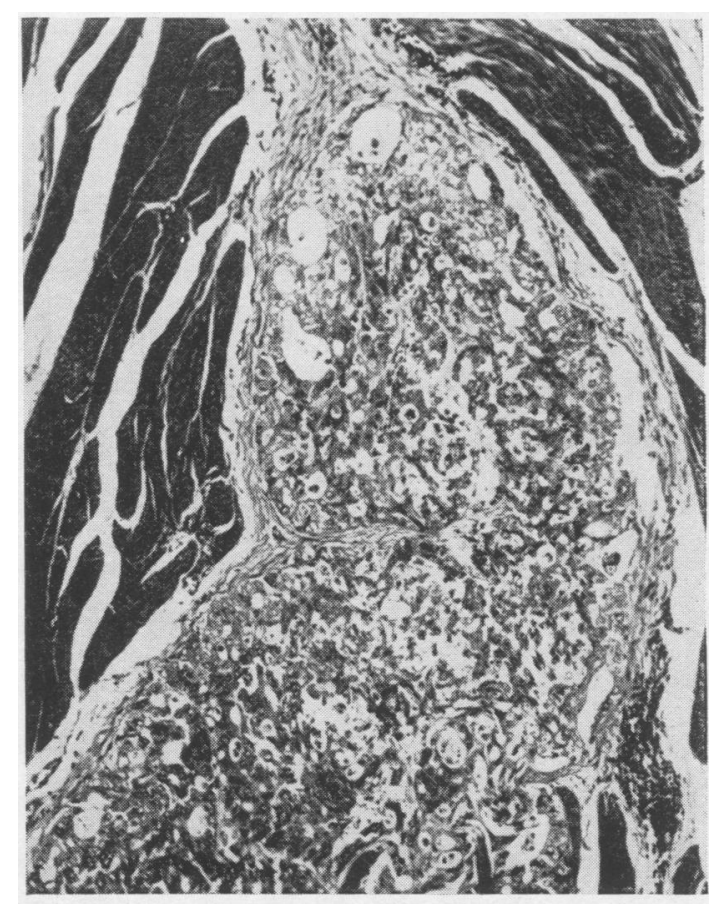

Fig.7-Nodule of carcinoma cells deep in the musculature of the bladder of dog $458 . \times 90$. 
On balance, therefore, it would appear that 4-aminodiphenyl is at least as active as a bladder carcinogen in the dog as $\beta$-naphthylamine, and considerably more potent than benzidine or 2acetylaminofluorene. Of the amines which have been shown to be active in this respect, only $\beta$-naphthylamine and benzidine have so far been manufactured on a large scale and both have been responsible for a high incidence of bladder cancer in the work people involved. Owing to the timely discovery by Wilson, De Eds, and Cox (1941) of the carcinogenic action of 2-acetylaminofluorene, this otherwise promising insecticide has not been manufactured commercially.

These considerations lend additional support to our suggestion in our earlier paper (op. cit.) that 4-aminodiphenyl played a part, together with $\beta$-naphthylamine and other high boiling aromatic amines, in the genesis of some of the bladder tumours in dyestuff workers which occurred in Germany during the early years of this century, and which have been attributed to aniline. We therefore conclude that its manufacture and handling today would carry with it grave risks to the working population involved unless adequate precautions were taken to avoid skin contact or the inhalation of vapour or dust by the use of totally enclosed plant and daily changes of clothing for the operatives.

\section{Summary}

After being given 4-aminodiphenyl by mouth in a total dose of 30 to $34 \mathrm{~g} \cdot(2 \cdot 9-3 \cdot 3 \mathrm{~g}$. per $\mathrm{kg}$.) the two Beagle dogs in our experiment were killed when they had advanced bladder tumours, two years nine months after the start of dosing.

This amine appears to be more effective as a bladder carcinogen in the dog than either benzidine or 2-acetylaminofluorene, and at least as potent as $\beta$-naphthylamine.

It is concluded that this substance should not be manufactured or handled in the chemical industry without the most stringent precautions.

We wish to thank Mrs. A. B. Hallam for her help in dosing the animals.

\section{REFERENCES}

Bonser, G. M. (1943). J. Path. Bact, 55 ,

Gehrmann G. H., Foulger, J. H., and Fleming, A. J. (1949). Proceedings of the 9th International Congress on Industrial ceedings of the 9th International Congress on

Medicine, London, 1948, p. 472. Wright, Bristol.
Hofman, A. W. (1862). C.R. Acad. Sci., Paris, 55, 901.

Hueper, W. C., and Wolfe, H. D. (1937), Paris, Amer. J. Path., 13, 656. , Wiley, F. H., and Wolfe, H. D. (1938). J. industr. Hyg., 20,46 Morris, H.'P., and Eyestone, W. H. (1953). J. nat. Cancer Inst., 13,1139 .

Nelson, A. A., and Woodard, G. (1953). Ibid., 13, 1497.

Spitz, S. Personal communication.

, Maguigan, W. H., and Dobriner, K. (1950). Cancer, 3, 789.

Walpole, A. L., Williams, M. H. C., and Roberts, D. C.' (1952) British Journal of Industrial Medicine, 9, 255. Wilson, R. H., De Eds, F., and Cox, A. J., Jnr. (1941). Cancer Res., 